\title{
Blood glucose is unlikely to be a prognostic biomarker in acute colitis with systemic inflammatory response syndrome in Thoroughbred racehorses
}

\author{
Shuntaro URAYAMA ${ }^{*}$, Daisuke ARIMA ${ }^{1}$, Fumiaki MIZOBE ${ }^{2}$, Yuta SHINZAKI ${ }^{2}$, \\ Motoi NOMURA ${ }^{2}$, Yohei MINAMIJIMA ${ }^{3}$ and Kanichi KUSANO ${ }^{1}$ \\ ${ }^{1}$ Racehorse Hospital, Miho Training Center, Japan Racing Association, Ibaraki 300-0493, Japan \\ ${ }^{2}$ Racehorse Hospital, Ritto Training Center, Japan Racing Association, Shiga 520-3085, Japan \\ ${ }^{3}$ Laboratory of Racing Chemistry, Tochigi 320-0851, Japan
}

Although hyperglycemia at admission with colic has been reported to have a poor prognosis, there is no report specifically about acute colitis with systemic inflammatory response syndrome (SIRS) in horses. In this study, we measured blood glucose (Glu), insulin (Ins), and cortisol (Cor) levels in 17 Thoroughbred racehorses diagnosed as having acute colitis with SIRS, and examined the relationship between time-dependent changes in Glu, Ins, and Cor and prognosis. Glu levels were high in 3 horses at admission, but thereafter no horses had persistently high Glu levels. There was no significant difference in Glu, Ins, and Cor levels within $72 \mathrm{hr}$ between surviving and non-surviving horses. In conclusion, the Glu level is unlikely to be a useful prognostic biomarker in acute colitis with SIRS.

Key words: colitis, glucose, SIRS, Thoroughbred

\author{
J. Equine Sci. \\ Vol. 29, No. 1 \\ pp. 15-19, 2018
}

Acute colitis occurred in 158 horses at the Training Centers of the Japan Racing Association (JRA) over the 10 years from 2004 to 2014 . Its high fatality rate of $31.6 \%$ (unpublished data) is a major source of loss of racehorse resources, which is a common problem in the horse racing industry. Severe colitis in horses is caused by a number of stress factors, including long duration or distance of transportation, surgery, and changes in intestinal flora due to antimicrobial administration [4]. Horses with the disease have not only acute diarrhea but also a high body temperature and leukopenia with a left shift; they are therefore considered to have developed systemic inflammatory response syndrome (SIRS) [2, 17]. In equine colitis, loss of intestinal mucosal barrier function causes lipopolysaccharide (LPS) — a bacterial constituent - to enter the bloodstream, resulting in SIRS $[16,19]$. Severe or prolonged SIRS causes multiple organ failure and laminitis $[2,3]$. Equine SIRS is diagnosed when

Received: September 19, 2017

Accepted: October 20, 2017

*Corresponding author. e-mail: Shuntaro_Urayama@jra.go.jp (C)2018 Japanese Society of Equine Science

This is an open-access article distributed under the terms of the Creative Commons Attribution Non-Commercial No Derivatives (by-nc-nd) License. (CC-BY-NC-ND 4.0: https://creativecommons.org/licenses/ by-nc-nd/4.0/) two or more of the following four clinical parameters are met: hyperthermia or hypothermia, tachycardia, tachypnea, leukocytosis, and leukopenia [5, 17]. A recent study has reported that the term SIRS is appropriate for equine endotoxemia [17].

Human patients with SIRS and sepsis often develop hyperglycemia [12, 14]. This occurs because many of the inflammatory mediators induce gluconeogenesis and enhance glycogen catabolism, thus increasing insulin resistance. Development and continuation of hyperglycemia reduce the phagocytic and bactericidal activities of polymorphonuclear leukocytes and the ability to resist infection. Mitochondrial dysfunction can then trigger multiple organ failure. Therefore, in the human medical field, glycemic control is used as an adjunct therapy for SIRS and sepsis $[12,21]$.

Recent studies have reported the impact of hyperglycemia on the prognosis of horses with severe disease, as has been studied in humans $[6,8,9,18]$. Blood glucose concentrations at admission have been revealed to be associated with survival to hospital discharge in horses with colic, with higher blood glucose concentrations being associated with a less favorable prognosis [8]. However, as far as we know, no studies have focused on changes in blood glucose levels or investigated the relationship between these changes and prognosis in acute colitis in horses. 
Table 1. Characteristics on admission of 17 horses presented for acute colitis with SIRS

\begin{tabular}{lcc}
\hline \multicolumn{1}{c}{ Variable } & Survivors & Non-survivors \\
\hline $\mathrm{N}$ (male) & $9(7)$ & $8(6)$ \\
Age & $3(2-5)$ & $3(2-5)$ \\
Vital signs & $39.0(38.6-40.0)$ & $39.6(37.8-41.0)$ \\
Temperature $\left({ }^{\circ} \mathrm{C}\right)$ & $48(40-60)$ & $60(40-100)$ \\
Heart rate $($ beats/min) & $20(12-24)$ & $22(12-40)$ \\
Respiratory rate $($ breaths $/ \mathrm{min})$ & & \\
Blood data & $5,400(2,000-15,500)$ & $5,800(1,800-19,900)$ \\
White blood cell count $\left(\times 10^{2} / \mu l\right)$ & $52.0(37.4-62.8)$ & $61.6(43.5-80.3)$ \\
Hematocrit $(\%)$ & $106(92-187)$ & $110(69-128)$ \\
Glucose $(\mathrm{mg} / \mathrm{d} l)$ & $9.6(5.6-65.8)$ & $19.9(4.1-49.4)$ \\
Insulin $(\mu \mathrm{U} / \mathrm{m} l)$ & $142.5(42.4-260)$ & $182.0(38.6-212)$ \\
Cortisol $(\mathrm{ng} / \mathrm{m} l)$ &
\end{tabular}

Data are reported as numbers $(\mathrm{N})$ or medians.

In this study, we measured blood glucose (Glu), insulin (Ins), and cortisol (Cor) levels in 17 horses diagnosed as having acute colitis with SIRS and examined the relationship between time-dependent changes in Glu, Ins, and Cor and prognosis.

The subjects were Thoroughbred racehorses housed at the Ritto and Miho Training Centers of the JRA between May 2015 and August 2016. Of the horses that had acute colitis with fever and watery diarrhea at admission, 17 that met two or more of the following parameters were examined: high body temperature $\left(\mathrm{T}>38.6^{\circ} \mathrm{C}\right)$, tachycardia $(\mathrm{HR}>60 \mathrm{bpm})$, tachypnea (RR $>30 \mathrm{bpm}$ ), and leukocytosis or leukopenia (WBC count $>12,500$ or $<4,500$ cells $/ \mu l$ ) [5]. We classified the horses into two groups on the basis of prognosis: a non-survivor group ( 8 horses), in which horses died without responding to treatment or were euthanized, and a survivor group ( 9 horses), in which horses were cured by treatment. Blood was collected every 12 from $0 \mathrm{hr}$ (at admission) to $72 \mathrm{hr}$ from all horses except 3 horses that died within $72 \mathrm{hr}$. We used blood collection tubes to which sodium fluoride, sodium citrate, and EDTA-2Na had been added $(7 \mathrm{ml}$; VENOJECT II, Terumo, Tokyo, Japan) for plasma separation and plain blood collection tubes $(15 \mathrm{~m} l$; VENOJECT II, Terumo) for serum separation, and we centrifuged both types of tubes at 3,000 rpm for $10 \mathrm{~min}$. The plasma and serum were stored at $-80^{\circ} \mathrm{C}$ until measurement. We examined Glu, Ins, and Cor as biomarkers of the mechanism of blood glucose regulation. Plasma Glu was measured by using a DRI-CHEM $7000 \mathrm{Z}$ automated clinical chemistry analyzer (Fujifilm Corp., Tokyo, Japan). Plasma Ins was measured by using a Mercodia Equine Insulin ELISA Kit (Mercodia AB, Uppsala, Sweden). Serum Cor was measured by using high-performance liquid chromatography (Prominence, Shimadzu, Kyoto, Japan) and a tandem mass spectrometer (4000 QTRAP, Sciex, Framingham, MA, U.S.A.) system.
We used Excel V7 for statistical analysis. Data are presented in graphs by using mean values \pm standard error. On the basis of previous reports $[7,8,20]$, the normal ranges were set at 75.6 to $131.4 \mathrm{mg} / \mathrm{d} l$ (Glu), 4.1 to $4.5 \mu \mathrm{U} / \mathrm{m} l$ (Ins), and 61 to $85 \mathrm{ng} / \mathrm{m} l$ (Cor). Values deviating from these ranges were interpreted as abnormal. We used the Mann-Whitney $U$-test for intergroup comparison of measurement results and the $F$-test for variance comparison. A significance level of $P<0.05$ was considered statistically significant.

The median values of the measurement results at admission of all 17 horses were as follows: Glu=109 mg/ $\mathrm{d} l$, Ins $=12.8 \mu \mathrm{U} / \mathrm{m} l$, and Cor $=169.5 \mathrm{ng} / \mathrm{m} l$ (Table 1 ). The plasma Glu and serum Cor levels of each horse are shown in Fig. 1. Because blood collection times were inconsistent within $24 \mathrm{hr}$ after the onset of colitis, the maximum and minimum values are presented. Data on 3 of the 17 horses were excluded from the figures and tables, because these 3 horses were not able to undergo serial measurement of Ins and Cor. Although 3 horses in the survivor group had increased Glu levels ( $>131.4 \mathrm{mg} / \mathrm{d} l)$ at $0 \mathrm{hr}$ (at admission), no horses in either group had persistently increased Glu levels. In addition, there was no significant difference in Glu levels between the two groups. No correlation was found between Glu level and prognosis (Fig. 1). Ins levels at $0 \mathrm{hr}$ were high $(>4.5 \mu \mathrm{U} / \mathrm{m} l)$ in 14 horses (data excluded the 3 mentioned above). Cor levels were high ( $>85 \mathrm{ng} / \mathrm{m} l)$ in 6 of 8 horses (survivor group) and 3 of 6 horses (nonsurvivor group); Cor levels were persistently high in the first $24 \mathrm{hr}$ in 2 of 6 horses (survivor group) and 3 of 3 horses (non-survivor group). After $24 \mathrm{hr}$, both Ins and Cor levels decreased gradually to normal levels.

In both humans and horses, Cor levels usually increase as a stress response, promoting gluconeogenesis in the liver. As a result, blood glucose levels increase, inducing insulin secretion [14]. Insulin secreted in association with increasing 

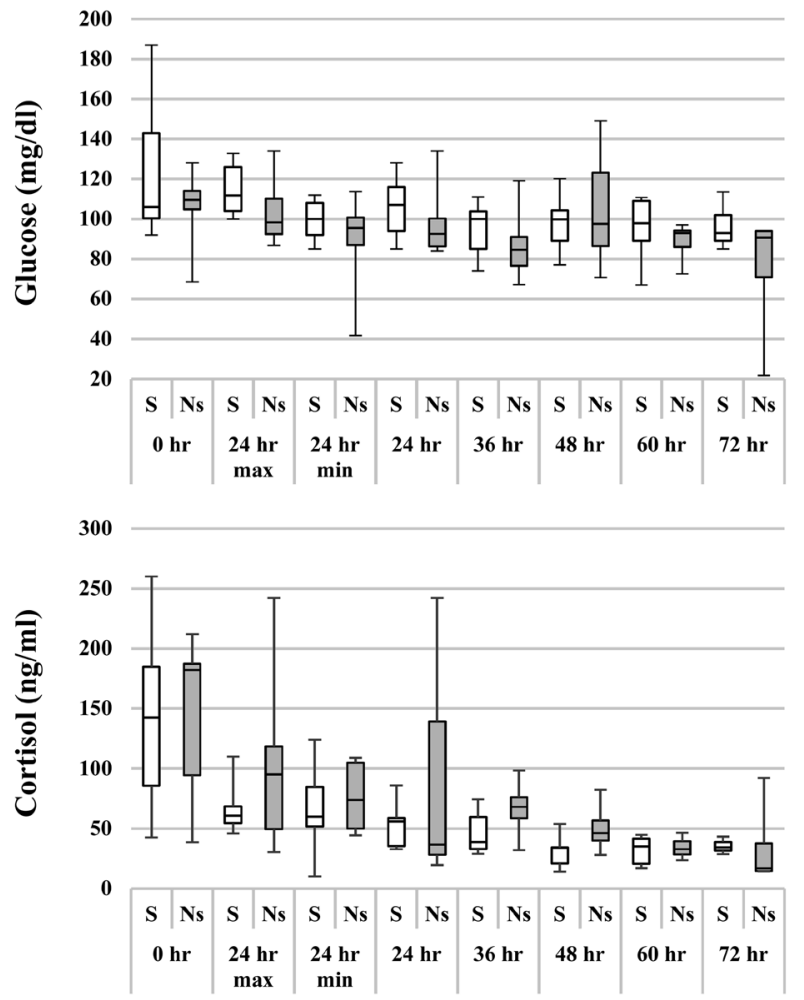

blood glucose levels acts on insulin receptors on the cell surface and binds to insulin receptor substrate-1 (IRS-1) to become tyrosine phosphorylated. The phosphorylated IRS-1 binds to phosphatidylinositol 3 kinase (PI-3-kinase), which transfers glucose transporters to the cell membrane and incorporates glucose into the cells. This prevents hyperglycemia and maintains normal blood glucose levels [14]. Insulin resistance associated with hyperglycemia in horses is caused by impaired activation of PI-3-kinase [22]. Here, we found that although Cor levels increased transiently, Ins levels increased at the same time, and Glu therefore did not increase in most horses. These findings suggest that because Ins responded to the increased Glu levels at admission, the horses were not considered to have insulin resistance; therefore, the mechanism of blood glucose regulation was likely to have been functioning properly.

Horses with acute abdomen have hyperglycemia, as is the case in seriously ill human patients, and high blood glucose levels at admission affect the prognosis in horses with acute abdomen [8]. The changes we found in blood glucose levels differed from those in a previous study [8]. This was because the previous study included horses with acute abdomen requiring surgery — not just colitis—and $\alpha 2$ agonists with a blood glucose-increasing effect were used in many of the horses before blood collection.

We examined changes in plasma glucose levels by setting

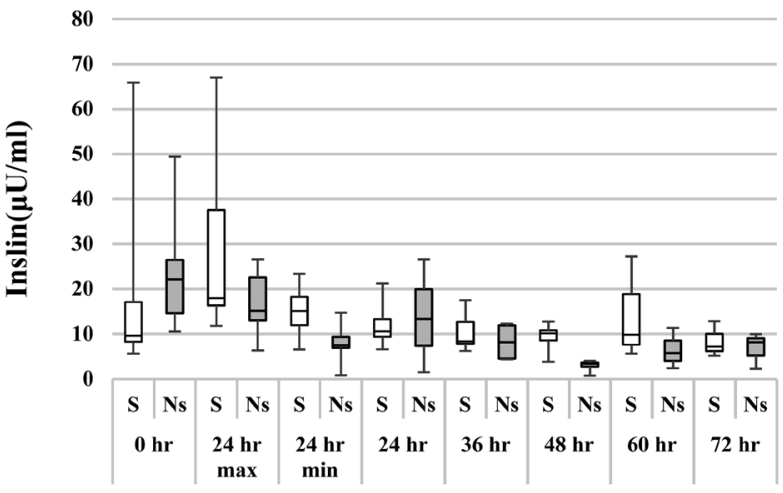

Fig. 1. Changes in blood glucose, insulin, and cortisol levels in horses with acute colitis and SIRS between 0 and $72 \mathrm{hr}$ after presentation. The center line is the median; interquartile ranges and maximum and minimum values are represented by boxes and whiskers. No values differed between survivors and non-survivors. S, survivor; Ns, non-survivor. Reference ranges: glucose $=75.6$ to 131.4 $\mathrm{mg} / \mathrm{d} l$, insulin $=4.1$ to $4.5 \mu \mathrm{U} / \mathrm{m} l$, cortisol $=61$ to $85 \mathrm{ng} / \mathrm{m} l$.

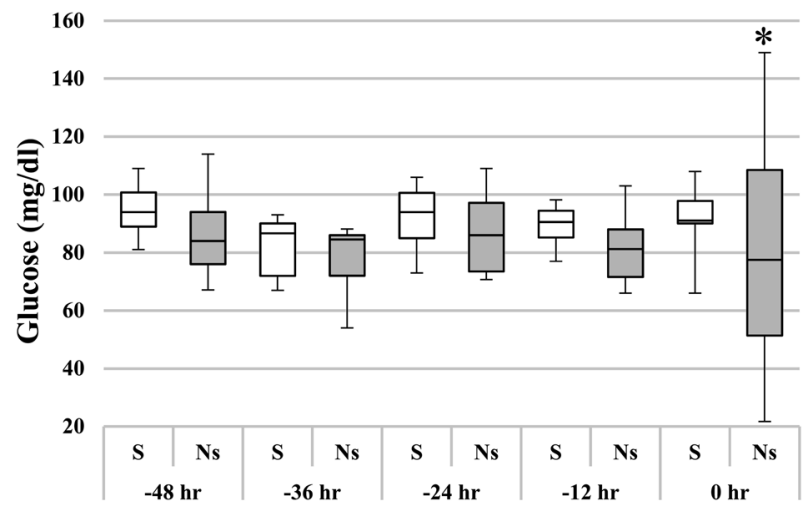

Fig. 2. Changes in blood glucose in horses with acute colitis with SIRS, counted backward from an outcome point ( $0 \mathrm{hr})$ in time. The center line is the median; interquartile ranges and maximum and minimum values are represented by boxes and whiskers. In the non-survivor group, the blood glucose concentration changed markedly between $-12 \mathrm{hr}$ and $0 \mathrm{hr}$. *Outcome significantly different $(P<0.05 ; F$-test $)$ from that in the survivor group. S, survivor group; Ns, non-survivor group.

the outcome point as $0 \mathrm{hr}$ and calculating the time backward (Fig. 2). In Fig. 2, $0 \mathrm{hr}$ indicates the end of treatment in the survivor group and the time of last blood sampling before death or euthanasia in the non-survivor group. At $0 \mathrm{hr}$, the 
variance in glucose levels in the non-survivor group was significantly larger than that in the survivor group $(P<0.05)$. In the non-survivor group, blood glucose levels changed considerably in the $12 \mathrm{hr}$ before the terminal stage. It was considered that multiple organ failure caused dysfunction of the blood glucose regulation mechanism, resulting in large fluctuations in blood glucose levels in the terminal stage [11].

Equine SIRS with acute organ failure triggers septic shock; the blood pressure drops, and the horses develop multiple organ failure or die if they do not respond to infusions [18]. We found no significant difference in blood glucose levels between the survivor and non-survivor groups in the $72 \mathrm{hr}$ after admission. In the non-survivor group, the state of remarkable shock likely progressed before dysfunction of the blood glucose regulation mechanism, resulting in death.

In human and equine SIRS, CD14 (a co-receptor for bacterial LPS) and toll-like receptors (TLRs), which are expressed on the surface of peripheral blood monocytes, play important roles in mediating the body's response. The binding of LPS to the CD14-TLR4 complex is effective in generating a functional cellular response that triggers the production of inflammatory cytokines [1, 10, 13, 15, 17, 23]. However, the TLRs known to be produced as an endogenous immune response to infection are highly species specific [17]. Since the mechanism by which the immune system elevates blood glucose levels in response to systemic inflammatory reactions such as acute colitis likely differs between humans and racehorses, it is necessary to study it in the future.

In conclusion, there was no relationship between blood glucose level and prognosis in horses with colitis and SIRS. Racehorses with acute colitis rarely have hyperglycemia. Although we examined only 17 horses, we consider that the blood glucose level is unlikely to be a useful prognostic biomarker in acute colitis in Thoroughbred racehorses.

\section{References}

1. Akashi, S., Ogata, H., Kirikae, F., Kirikae, T., Kawasaki, K., Nishijima, M., Shimazu, R., Nagai, Y., Fukudome, K., Kimoto, M., and Miyake, K. 2000. Regulatory roles for CD14 and phosphatidylinositol in the signaling via tolllike receptor 4-MD-2. Biochem. Biophys. Res. Commun. 268: 172-177. [Medline] [CrossRef]

2. Anderson, S.L., and Singh, B. 2017. Neutrophil apoptosis is delayed in an equine model of colitis: Implications for the development of systemic inflammatory response syndrome. Equine Vet. J. 49: 383-388. [Medline] [CrossRef]

3. Belknap, J.K., Moore, J.N., and Crouser, E.C. 2009. Sepsis-From human organ failure to laminar failure. Vet. Immunol. Immunopathol. 129: 155-157. [Medline]
[CrossRef]

4. Cohen, N.D., and Woods, A.M. 1999. Characteristics and risk factors for failure of horses with acute diarrhea to survive: 122 cases (1990-1996). J. Am. Vet. Med. Assoc. 214: 382-390. [Medline]

5. Epstein, K.L., Brainard, B.M., Gomez-Ibanez, S.E., Lopes, M.A., Barton, M.H., and Moore, J.N. 2011. Thrombelastography in horses with acute gastrointestinal disease. $J$. Vet. Intern. Med. 25: 307-314. [Medline] [CrossRef]

6. Hassel, D.M., Hill, A.E., and Rorabeck, R.A. 2009. Association between hyperglycemia and survival in 228 horses with acute gastrointestinal disease. J. Vet. Intern. Med. 23: 1261-1265. [Medline] [CrossRef]

7. Hinchcliff, K.W., Rush, B.R., and Farris, J.W. 2005. Evaluation of plasma catecholamine and serum cortisol concentrations in horses with colic. J. Am. Vet. Med. Assoc. 227: 276-280. [Medline] [CrossRef]

8. Hollis, A.R., Boston, R.C., and Corley, K.T. 2007. Blood glucose in horses with acute abdominal disease. J. Vet. Intern. Med. 21: 1099-1103. [Medline] [CrossRef]

9. Hollis, A.R., Furr, M.O., Magdesian, K.G., Axon, J.E., Ludlow, V., Boston, R.C., and Corley, K.T. 2008. Blood glucose concentrations in critically ill neonatal foals. $J$. Vet. Intern. Med. 22: 1223-1227. [Medline] [CrossRef]

10. Kiku, Y., Kusano, K., Miyake, H., Fukuda, S., Takahashi, J., Inotsume, M., Hirano, S., Yoshihara, T., Toribio, R.E., Okada, H., and Yoshino, T.O. 2003. Flow cytometric analysis of peripheral blood mononuclear cells induced by experimental endotoxemia in horse. J. Vet. Med. Sci. 65 : 857-863. [Medline] [CrossRef]

11. Kyle, U.G., Coss Bu, J.A., Kennedy, C.E., and Jefferson, L.S. 2010. Organ dysfunction is associated with hyperglycemia in critically ill children. Intensive Care Med. 36: 312-320. [Medline] [CrossRef]

12. Langouche, L., and Van den Berghe, G. 2006. Glucose metabolism and insulin therapy. Crit. Care Clin. 22: 119-129, vii. [Medline] [CrossRef]

13. Lien, E., Means, T.K., Heine, H., Yoshimura, A., Kusumoto, S., Fukase, K., Fenton, M.J., Oikawa, M., Qureshi, N., Monks, B., Finberg, R.W., Ingalls, R.R., and Golenbock, D.T. 2000. Toll-like receptor 4 imparts ligand-specific recognition of bacterial lipopolysaccharide. J. Clin. Invest. 105: 497-504. [Medline] [CrossRef]

14. Marik, P.E., and Raghavan, M. 2004. Stress-hyperglycemia, insulin and immunomodulation in sepsis. Intensive Care Med. 30: 748-756. [Medline] [CrossRef]

15. Matsuda, N., and Hattori, Y. 2006. Systemic inflammatory response syndrome (SIRS): molecular pathophysiology and gene therapy. J. Pharmacol. Sci. 101: 189-198. [Medline] [CrossRef]

16. Milinovich, G.J., Klieve, A.V., Pollitt, C.C., and Trott, D.J. 2010. Microbial events in the hindgut during carbohydrateinduced equine laminitis. Vet. Clin. North Am. Equine Pract. 26: 79-94. [Medline] [CrossRef] 
17. Moore, J.N., and Vandenplas, M.L. 2014. Is it the systemic inflammatory response syndrome or endotoxemia in horses with colic? Vet. Clin. North Am. Equine Pract. 30: 337-351, vii-viii. [Medline] [CrossRef]

18. Pamela, A.W. 2009. Evolution and Future of Sepsis Treatment in Equine Emergency and Critical Care. AAEP Proceedings 55: 150-155.

19. Senior, J.M., Proudman, C.J., Leuwer, M., and Carter, S.D. 2011. Plasma endotoxin in horses presented to an equine referral hospital: correlation to selected clinical parameters and outcomes. Equine Vet. J. 43: 585-591. [Medline] [CrossRef]

20. Stull, C.L., and Rodiek, A.V. 1988. Responses of blood glucose, insulin and cortisol concentrations to common equine diets. J. Nutr. 118: 206-213. [Medline] [CrossRef] 21. van den Berghe, G., Wouters, P., Weekers, F., Verwaest, C., Bruyninckx, F., Schetz, M., Vlasselaers, D., Ferdinande, P., Lauwers, P., and Bouillon, R. 2001. Intensive insulin therapy in critically ill patients. N. Engl. J. Med. 345: 1359-1367. [Medline] [CrossRef]

22. Lacombe, V.A. 2014. Expression and regulation of facilitative glucose transporters in equine insulin-sensitive tissue: from physiology to pathology. ISRN Vet. Sci. 2014: ID409547. [Medline] [CrossRef]

23. Wright, S.D., Ramos, R.A., Tobias, P.S., Ulevitch, R.J., and Mathison, J.C. 1990. CD14, a receptor for complexes of lipopolysaccharide (LPS) and LPS binding protein. Science 249: 1431-1433. [Medline] [CrossRef] 